\title{
Transformational leadership as a factor in the success of knowledge-intensive companies
}

\author{
Aleksei Bogoviz ${ }^{1, *}$, Svetlana Lobova ${ }^{2,3}$, and Elena Popkova ${ }^{4}$ \\ ${ }^{1}$ Federal Research Center of Agrarian Economy and Social Development of Rural Areas - All \\ Russian Research Institute of Agricultural Economics, 123007, Khoroshevskoye shosse, 35k2, \\ Moscow, Russia \\ ${ }^{2}$ Altai State University, 656049, Lenin ave., 61, Barnaul, Russia \\ ${ }^{3}$ Ural State University of Economics, 629144, 8 Marta str., Ekaterinburg, Russia \\ ${ }^{4}$ Volgograd State Technical University, 400006, Degtyareva str., 2, Volgograd, Russia
}

\begin{abstract}
The paper analyzes general trends in the development of the knowledge economy and knowledge-intensive companies worldwide and in Russia particularly. First, we consider the distinctive features of the knowledge economy, such as the transformation of the labor process and the changing nature of the workforce, which largely affect the behavior of knowledge-intensive companies, whose sole business is innovation, and require new forms of leadership. Second, we analyze how transformational leadership affects creativeness and innovations in the knowledge-intensive companies on the basis of the recent scholarly research. Third, we argue that the transformational leadership style is most appropriate for the knowledgeintensive companies mainly due to its orientation on continuous development for the individual employees and the company as a whole. We conclude with key insights on the use of transformational leadership in the knowledge-intensive companies in Russia and worldwide.
\end{abstract}

\section{Introduction}

The knowledge economy leads to a fundamental restructuring of the economy and to a need in effective forms of leadership. Knowledge-intensive companies are on the edge of scientific and technical progress. In order to survive in a complex business environment, they have to constantly innovate and adapt to changes. This paper is aimed at understanding how knowledge-intensive companies can use transformational leadership in order to successfully compete in the complex business environment. I argue that transformational leadership can foster innovation in firms and create sustainable competitive advantage.

This paper is structured as follows. First, I discuss essential characteristics of the knowledge economy. Second, I identify how the knowledge economy affects knowledgeintensive companies in Russia and worldwide and what leadership issues it creates. Thirdly, I discuss the role of transformational leadership that highly influences organizational performance, creativity and innovation. The paper concludes with nine main insights on the role of transformational leadership in knowledge-intensive companies.

* Corresponding author: aleksei.bogoviz@gmail.com 


\section{Knowledge-intensive companies in the knowledge economy}

Leadership is a key factor that affects organizational performance. How do recent economic developments influence business companies and their leadership strategies? In the following section, I focus on the essential characteristics of the knowledge economy with respect to knowledge-intensive companies. I argue that the transition to the knowledge economy is characterized by qualitative transformations of the labor process and the emergence of a new type of labor force, which also requires new forms of leadership.

The knowledge economy has a number of distinct characteristics in comparison with the industrial economy, such as (i) highly unstable waves of innovation, (ii) the interlinked nature of products and services, and (iii) the interdisciplinary complexity of the process of production [24]. Consequently, companies' success in the knowledge economy becomes highly dependent not only on the proven approaches to business but even more dependent on companies' abilities to transform the available methods and obtain necessary results under rapidly changing market conditions.

Zanini \& Musante state that the knowledge economy is characterized by constant change and innovations [32]. Therefore, the knowledge economy creates a new business environment, which is characterized by high uncertainty and risks, forcing businesses to constantly adapt to changes in their systems. The production of capabilities becomes dependent on effective coordination within relationship network, which allows for greater production flexibility and information availability [32].

Another business dynamic caused by the economy of knowledge leads to very high market competition between the companies. According to Zanini \& Musante, "A firm's success is highly correlated with its ability to quickly develop and market new products" [32]. Consequently, the role of creativity and constant innovations increases greatly in the knowledge economy. In other words, "[firms'] performance depends not only on the capacity to create marketable goods and services, but also on the capacity to adapt to environmental changes in a way that maximizes workforce operations" [32].

Modern post-industrial societies value the intangible intellectual capital and the resource of knowledge. As a consequence, successful companies rely on the use of knowledge capital as their market competitive advantage. Knowledge capital supports competencies, and they, in turn, support the products and services supplied by the firm to the market [28]. In the previous industrial era, the main resources of the companies were physical, tangible and limited. In the new knowledge economy, resources cannot be considered in the same terms. According to Orlikowski, knowledge should be viewed as a continuous, unstable social achievement, existing temporary and being created and reconstructed in everyday practices [22]. Therefore, leadership strategies based on regularity, measurability, predictability and control does not lead to high performance as they do in the industrial era. In the knowledge economy, leaders should take into consideration the nature of labor based on knowledge and practice approaches that stimulate employees to produce new ideas and lead to high performance.

Another challenge in the knowledge economy comes from changes in the nature of the workforce. A new labor force is entering the labor market, which consists of people who prefer equitable relations with the company and have a greater level of independence and technical literacy [12]. In my perspective, the employees of the knowledge economy are highly educated people, who can know more about the company and its industries than their managers. Therefore, effective leadership needs to acknowledge this fact and mobilize the distribution of knowledge among their followers. Zanini \& Musante also state that firms need to constantly change due to high market uncertainties [32]. The need to constantly adapt to complex environments also requires the presence of such a workforce that is able to quickly reorganize and redeploy internal resources [32]. Therefore, companies operating in the 
knowledge economy have to adapt certain leadership strategies that allow them to achieve necessary outcomes and provide constant organizational changes.

Being highly concerned about future sources of economic growth and wealth, many developing countries have policies for gradually developing their national economies in the direction of innovation-driven economy. It is widely considered that future economic growth will be based on innovation-induced productivity. Gackstatter considers "a powerful knowledge base, often centered on technology and innovation, as an important precondition for building and developing a genuine innovation economy" [9]. Also, Gackstatter states that "economists recognize that knowledge-based innovation is a major driver of competitiveness" [9]. Getting more specific, Doroshenko, Miles \& Vinogradov emphasize that knowledge-intensive companies are an inevitable part of the knowledge economy and "already play an important role in developed economies" [6]. These companies are not only innovative themselves in their nature, but also have a function of providing valuable knowledge to other economic actors [6].

In other words, knowledge-intensive companies include those firms that have to adapt to deep and rapid changes in the knowledge economy very quickly, stimulate risk taking and innovativeness in response to the environment's uncertainty and turbulence. Therefore, knowledge-intensive companies by their nature have to be more creative and innovative in order to survive in this environment. In order to cope with necessary changes by stimulating creativity and innovation, knowledge-intensive companies need to rely on an effective style of leadership. I think that transformational leadership is most appropriate for the knowledgeintensive companies mainly due to its orientation on continuous development for the individual employees and the company as a whole. In the following section, I review main characteristics of transformational leadership and identify how this leadership style affects companies' performance by stimulation creativity and innovation.

\section{Transformational leadership for knowledge-intensive companies: addressing the challenges of complex environments}

The concept of "transformational leadership" was first introduced by J. McGregor Burns as the opposite to "transactional leadership," another leadership style. According to Burns, transformational leadership creates significant positive changes in followers' behaviors, stimulating them to higher levels of morality and motivation [3]. The followers feel trust, admiration, and respect towards their leaders; they strive to perform beyond expectations. In the paradigm of transformational leadership, organizational changes are based on a common vision and shared goals. In contrast, "transactional leadership" is based on traditional approaches to management through task setting and performance monitoring. I believe that transformational leadership meets the requirements for leaders in the knowledge economy in the very best way due to its essential characteristics. In following part of the paper, I review some mechanisms used by transformational leaders to have a positive impact on organizational performance, primarily focusing on knowledge-intensive companies and their innovative outcomes.

Many scholars prefer to analyze the relationship between leadership styles and companies' performance by looking at indirect correlations between them. For instance, Garcia-Morales et al. explore the links between transformational leadership and organizational performance, stating that there are two mediators, namely (i) organizational learning and (ii) innovation [11]. She defines organizational learning as "the capability within an organization to maintain or improve performance based on experience" [11]. The process of organizational learning consists of three steps: (i) knowledge acquisition; (ii) knowledge 
sharing; and (iii) knowledge utilization [11]. Therefore, the ultimate goal of organizational learning is "to establish a path for professional development to acquire aptitudes or competencies that give sustainable advantage through innovation" [11].

I agree with Carcia-Morales et al. that organizational learning should be focused on cognitive and behavioral change as a final outcome of the whole process. Enterprises can accelerate the process of organizational learning by developing new knowledge, abilities and increasing organizational capacity [11]. Garcia-Morales et al. are absolutely sure that transformational leadership can significantly improve organizational performance that is greatly affected by rapidly changing business environments [11]. Their empirical study shows that "a management style of transformational leadership through organizational learning and innovation simultaneously influences organizational performance" [11]. GarciaMorales et al. (2012) state that the process of organizational learning is greatly affected by transformational leadership that "analyzes, modifies, and drives systems, designing them to share and transfer knowledge" [11]. In their opinion, "Transformational leadership becomes the motor and transmitter of innovative culture and of the dissemination of knowledge oriented to seeking the best possible organizational performance" [11]. Thus, I can summarize that transformational leadership minimizes the cost of internal change, which is crucial for knowledge-intensive industries, and helps construct competencies that are focused on organizational learning.

Limiting his focus to a specific characteristic of transformational leadership, Paulsen (2009) studies research and development teams, exploring how the charismatic dimension of transformational leadership actually influences team innovations [23]. A charismatic style of transformational leadership supports team innovation by "promoting team innovation by supporting a sense of team identity and commitment" and "encouraging team members to cooperate through expression of ideas and participation in decisions" [23]. This style of leadership has positive impact on the teams, facilitating interactions between them According to Paulsen, "Teams with a strong team identity combined with the exercise of cooperative behaviors are more innovative" [23]. In short, the effect of transformational leadership on team innovations is found to be partially mediated by organizational identification.

Conducting a country-specific research, Samad focuses on the relationship between transformational leadership, innovation, and organizational performance. Focusing on Malaysian knowledge-intensive companies, he proves statistically that transformational leadership and innovation significantly influence organizational performance [25]. Samad concludes that transformational leadership and organizational performance are "the key component of internal resources in securing competitive advantage and achieving organizational performance" [25].

Another prominent researcher focuses on corporate entrepreneurship as a mediator between leadership and performance. Chen studies the relationship among firm's innovation performance, corporate entrepreneurship, and transformational leadership. She defines corporate entrepreneurship as "the aggregation of a firm's renewal and venturing efforts" [5]. Transformational leadership is positively related to corporate entrepreneurship because of several factors, including the following (i) encouraging the followers to "develop new market ventures or products"; (ii) motivating the followers to "develop self-confidence and efficiency" and "willingness to perform beyond expectations" [5]. Thus, Chen concludes that "corporate entrepreneurship may have a significant mediating effect on the relationship between a firm's transformational leadership and its product innovation performance" [5].

Moreover, another mediator between transformational leadership and corporate entrepreneurship, technology orientation, is studied by [5]. "Technology orientation is incorporated into a "firm's decision-making and organizing process" and "indicates a tendency to support new ideas and the adoption of new technology" [5]. If a firm is highly technology-oriented, it has a predominant focus on such activity and place heavy emphasis 
on generating new ideas or adopting new methods and advanced technologies, which in turn can enhance corporate entrepreneurship [5].

Chen supports her theory by conducting an empirical research in China, which shows that transformational leadership enhances product innovation performance through entrepreneurship [5]. Chen considers transformational leadership as "an important antecedent to the development of corporate entrepreneurship," and innovation performance is an important consequence of the latter [5]. To summarize, technology orientation provides the conditions for transformational leadership to get transformed into actual entrepreneurial activities. Consequently, knowledge-intensive companies should pay a lot of attention to technology orientation in order to constantly innovate and be competitive on the market.

I think that large- $\mathrm{N}$ studies on transformational leadership within a cross-cultural context would provide valuable insights on innovative outcomes in knowledge-intensive companies. In their intercultural study on 790 small and medium-sized firms, Engelen, Strenger \& Brettel identify the four key transformational behaviors, such (i) "articulating a vision"; (ii) "providing an appropriate model"; (iii) "having high performance expectations"; and (iv) "showing supportive leader behavior" [8]. These transformational behaviors positively affect the relationship between entrepreneurial orientation and firm performance, creating a special environment that eliminates resistance to new ideas among the followers [8].

Engelen, Strenger \& Brettel go through each of the four key mechanisms. First, articulating a clear vision leads to a greater commitment to firm's interests and higher responsibility among the followers [8]. Second, providing an appropriate model of behavior makes the communication between leaders and their followers better as well as increases trust in them. Third, setting high expectations males the employees motivated to reach the very best results and stay ahead on the market. Fourth, supportive behavior shows how much leaders take care of their followers. Also, they state that intellectual stimulation encourages to challenge the status quo, providing more opportunities for approaching conventional wisdom in a new way and reframing existing assumptions [8].

Another level of the transformational leadership-technological innovation relationship is analyzed by [4]. In his study [4], Chen focuses on the relationship between transformational leadership on the level of strategic business units and technological innovation Innovative culture and incentive compensation serve as moderators in this relationship, making innovative outcomes more likely to occur. In particular, Chen argues that the moderators can have different influence on the effectiveness of transformational leadership in promoting firms' innovativeness [4]. Therefore, "by focusing on how moderators operate, managers can identify organizational situations that facilitate greater innovation outcomes" [4]. In short, business units are required to change or improve product or service features in order to meet market needs and being able to improve the efficiency of product development and commercialization.

Given an increasing role of interdisciplinary approaches in social sciences, I am very interested in the research conducted by Aryee et al., which focuses on finding psychological mechanisms and conditions through which transformational leadership impacts followers' beneficial work behaviors. They find that employees' experienced meaningfulness and responsibility may serve as such mediators [1]. The research defines experienced meaningfulness as "a degree to which an employee experiences the work as inherently meaningful, judged in relation to an individual's own ideals or standards" [1]. Since transformational leadership unites the followers in order to achieve a common goal, we may propose that employees experience more meanings in working together. In turn, experienced responsibility is "a degree to which an employee feels personally accountable and responsible for the results of the work" [1]. Transformational leaders, according to Aryee et al., encourage their followers to take more responsibilities through (i) paying more attention to employee's needs and (ii) building a sense of control through shared power" [1]. Work engagement is a 
product of employees' experienced meaningfulness and responsibility and positively influences innovative behavior and task performance [1]. To summarize, transformational leaders need to foster psychological states of experienced meaningfulness and responsibility in order to stimulate employee's innovative behaviors.

Moriano et al. focus on organizational identification as a mediator between transformational leadership and intrapreneural behavior [20]. In their research, Moriano et alstate that companies should stimulate "intrapreneural behavior" among their employees in order to succeed on highly competitive markets, focusing on taking high risks and pushing innovative projects [20]. More than that, the study shows that organizational identification serves as a mediator between transformational leadership and intrapreneural behaviour [20]. Therefore, transformational leaders create and promote a sense of on organizational mission, linking follower's identities to the collective identity and increasing their motivation to perform much better [20]. To summarize, transformational leadership is the most important organizational factor that highly influences intrapreneurship through strengthening organizational identification.

Brauna et al. explore the multilevel relationship between transformational leadership, trust in supervisor and team, and team performance. They state that trust in supervisor and team is a mediator between transformational leadership and better team performance, which is understandable due to organizations' predominantly team-based structure [2]. In turn, transformational leadership positively affects job satisfaction and consequently increases employees' performance. Transformational leaders stimulate both individual-focused and team-focused positive behaviors, affecting organization's performance at multiple levels [2].

Any large organization working in a highly competitive environment is a complex entity itself. I think that one should look at more complex interactions between transformational leadership and organization's performance in order to understand caudal mechanisms. I find $\mathrm{Hu}, \mathrm{Gu} \&$ Chen's research [17] quite helpful for understanding the nature of such complex interactions. In particular, they review a number of indirect ways used by transformational leadership to influence organizational creativity and innovation. $\mathrm{Hu}, \mathrm{Gu} \&$ Chen believes that a great number of these indirect ways exists at three different levels [17]. At the first level, individual, psychological empowerment, intrinsic motivation, creative self-efficacy, conservation, organization-based self-esteem, and self-presentation propensity play the very important role [17]. At the second level, collective, other factors, such as collective efficacy, knowledge sharing, and support for innovation and climate for excellence, mediate the relationship between transformational leadership and organizational performance [17]. And at the third level, organizational, other factors mediate this relationship, including organizational climate, empowerment through autonomy and freedom, and organizational learning [17].

In short, transformational leadership is very appropriate for knowledge-intensive companies. The most important feature of this style is its orientation on development and not on functioning. Transformational leadership creates optimal conditions for the development of both individual employees and a firm as a whole, which is a necessary condition for sustainable successful work in the knowledge economy.

\section{Conclusion}

The knowledge economy leads to cardinal changes in the workforce, and the continuous development of scientific and technological progress have a strong impact on leadership practices in those companies that building their success on knowledge and innovations. The literature review shows that transformational leadership can affect organizational performance in a great number of ways. I would like to highlight the key insights from the 
literature on transformational leadership and organizational performance with the focus on knowledge-intensive companies.

First, transformational leaders influence the basic attitudes and values of employees in organizations, creating a shared picture of reality that allows the last to successfully achieve organizational goals.

Second, many empirical studies reviewed above clearly demonstrate transformational leadership positively influences organizational performance and increases organizations' innovativeness, creating lasting and sustainable advantages.

Third, transformational leadership allows creating a shared vision for all employees in an organization. In turn, it motivates workers to create and share knowledge, increasing their laying the foundations for an innovative culture.

Forth, due to the fact that companies employ more and more intellectual workers and are increasingly confronted with tasks that have intellectual content, the process of implementing many procedures requires more creativity rather than applying a standard, conventional procedure.

Fifth, in a situation of such uncertainty, transformational leaders strengthen the search for new opportunities, as well as the process of creating a shared vision and high motivation for employees. The search for new opportunities inspires employees to assume greater responsibility and rely on implicit knowledge in the work more often.

Sixth, the firms in knowledge-intensive industries and beyond need to adapt more quickly to the increasing number of changes in a more complex environment than ever before. The process of adaptation requires a greater ability to absorb the best practices and knowledge from both the external environment and the firm itself. Transformational leaders provide information, assign responsible tasks, and contribute to the development of competencies of all employees involved in organizational activities in order to reduce internal barriers.

Seventh, transformational leadership by its nature implies the active development of the process of organizational learning. Therefore, it becomes a key factor for the success of firms in the knowledge economy through the use of intellectual capital. Transformational leadership allows firms' employees to actively learn through experimentation, communication, and dialogue, constantly improving personal skills and creating organizational knowledge.

Eights, transformational leadership plays a key role in creating an organizational climate that, in turn, generates innovation and practices for such generation.

Ninth, transformational leadership creates organizational identity that stimulates its employees to perform to their best results.

The reported research was funded by the Russian Foundation for Basic Research and the Government of the Altai region, grant No 18-410-220015.

\section{References}

1. S. Aryee, F. O. Walumbwa, Q. Zhou, C. A. Hartnell, Human Performance, 25, 1 (2012)

2. S. Brauna, C. Peusb, S. Weisweilera, D. Freya, The Leadership Quarterly, 24, 1 (2013)

3. J. M. Burns, Leadership (New York, Harper and Row, 1978)

4. M. Y. C.Chen, C. Y. Y. Lin, H. E. Lin, E. F. McDonough, Asia Pacific Journal of Management, 29, 2 (2012)

5. Y. Chen, G. Tang, J. Jin, Q. Xie, J. Li, Journal of Product Innovation Management, 31, 1 (2014)

6. M. Doroshenko, I. Miles, D. Vinogradov, Foresight-Russia, 8, 4 (2014) 
7. S. A.Eisenbeiß, S. Boerner, British Journal of Management, 24, 1 (2013)

8. A. Engelen, V. Strenger, M. Brettel, Journal of Management, 41, 4 (2015)

9. S. Gackstatter, Foresight, 16, 4 (2014)

10. S. Gackstatter, M. Kotzemir, D. Meissner, Foresight, 16, 4 (2014)

11. V. J. García-Morales, M. M. Jiménez-Barrionuevo, L. Gutiérrez-Gutiérrez, Journal of Business Research, 65, 7 (2012)

12. L. Grehtton, Demokraticheskoe predpriyatie. Raskreposhhenie biznesa blagodarya svobode, gibkosti i priverzhennosti (St. Petersburg, Stokgolmskaya shkola ekonomiki v Sankt-Peterburge, 2005)

13. A. Gromoff, Y. Bilinkis, N. Kazantsev, Global Journal of Flexible Systems Management, 18, 73, (2017)

14. D. Hayati, M. Charkhabi, A. Naami, Springerplus, 3 (2014)

15. R. M. Hechanova, R. Cementina-Olpoc, Asia-Pacific Education Researcher, 22, 1 (2013)

16. H.-C. Hsiao, J.-C. Chang, Asia Pacific Education Review, 12 (2011)

17. H. Hu, Q. Gu, J. Chen, Nankai Business Review International, 32, 7 (2012)

18. J. Kissi, A. Dainty, M. Tuuli, International Journal of Project Management, 31, 4 (2013)

19. J. R. Latham, Quality Management Journal, 21, 1 (2014)

20. J. A. Moriano, F. Molero, G. Topa, \& J.-P. L. Mangin, International Entrepreneurship and Management Journal, 10, 1 (2014)

21. N. Nusair, R. Ababneh, Y. K. Bae, International Journal of Commerce and Management, 22, 3 (2012)

22. W. J. Orlikowski, Organization Science, 13, 3 (2002)

23. N. Paulsen, V. J. Callan, \& O. Ayoko, Journal of Organizational Change Management, 26, 3 (2013)

24. D. Rooney, G. Hearn, T. Mandeville, R. Joseph, Public policy in knowledge-based economies: Foundations and frameworks (Cheltenham, Edward Elgar, 2003)

25. S. Samad, Procedia - Social and Behavioral Sciences, 57, 9 (2012)

26. Z. Shao, Y. Feng, L. Liu, Computers in Human Behavior, 28, 6 (2012)

27. S. Si, \& F. Wei, European Journal of Work and Organizational Psychology, 21, 2 (2012)

28. D. J. Teece, Managing intellectual capital: organizational, strategic and policy dimensions (Oxford: Oxford University Press, 2000)

29. S. Tipu, J. C. Ryan, K. A. Fantazy, Journal of Management \& Organization, 18, 4 (2012)

30. I. P. Tsapenko, M. A. Yurevich, Herald of the Russian Academy of Sciences, 84, 4 (2014)

31. H. Tse, W. Chiu, Journal of Business Research, 67, 1 (2014)

32. M. Zanini, M. Musante, Journal of Business and Industrial marketing, 28, 6 (2013) 